\title{
Blog power: Examining the effects of practitioner blog use on power in public relations
}

\author{
Lance V. Porter ${ }^{\mathrm{a}, *}$, Kaye D. Sweetser Trammell ${ }^{\mathrm{b}}$, Deborah Chung ${ }^{\mathrm{c}}$, Eunseong Kim ${ }^{\mathrm{d}}$ \\ a Manship School of Mass Communication, Louisiana State University, Baton Rouge, LA 70803-7202, United States \\ ${ }^{\mathrm{b}}$ Grady College of Journalism and Mass Communication, University of Georgia, Athens, GA 30602, United States \\ ${ }^{c}$ School of Journalism and Telecommunications, University of Kentucky, Lexington, KY 40506, United States \\ d Department of Journalism, Eastern Illinois University, Charleston, IL 61920, United States \\ Received 19 April 2006; received in revised form 12 September 2006; accepted 20 November 2006
}

\begin{abstract}
While blogs are not yet a standard public relations tool, practitioners use blogs to enhance their power within their organizations. Using an online survey of public relations practitioners, this pilot test examined the relationship between power and blog use. Three factored categorizations of blog use among practitioners emerged: routine information and research, interactive blog communication, and issues identification. Results showed differences based on power, between blog users and non-users, owner-practitioners and non-owners, among others.
\end{abstract}

C) 2007 Elsevier Inc. All rights reserved.

Keywords: Power; Blogs; Weblogs; Public relations practitioners; Web; Internet

\section{Introduction}

The Internet provides limitless opportunities for issues management, relationship management, environmental scanning, and other key public relations functions. Yet, researchers disagree on whether the potential and opportunities availed through the Internet are actually being used (Springston, 2001). As more Internet-based communication tools emerge and gain popularity, it behooves practitioners to understand how to integrate such tools early on. However, practitioners have been labeled "laggards" when it comes to technology (Anderson \& Regan, 1992; Porter, Sallot, Cameron, \& Shamp, 2001).

Weblogs, or blogs, represent a potentially useful communication technology for practitioners (Kelleher \& Miller, 2006). Considering the popularity of blogs, their potential to impact the media and public agenda (Drezner \& Farrell, 2004; Pew Internet \& American Life, 2005), and the credibility bloggers wield among readers (Johnson \& Kaye, 2004), it seems fitting that practitioners would not only begin monitoring blogs but engage them as they have traditional media outlets (Edelman \& Inteliseek, 2005).

This study extends the work of Porter and colleagues by examining power in relation to blogs (Sallot, Porter, \& Acosta-Alzuru, 2004; Porter \& Sallot, 2005). Here, researchers investigate how blogs factor in to practitioners'

\footnotetext{
* Corresponding author. Tel.: +1 225578 7377; fax: +1 2255782125.

E-mail addresses: lporter@1su.edu (L.V. Porter), kdt@uga.edu (K.D. Sweetser Trammell).
} 
structural, expert, prestige, and ownership power within their organizations (Finkelstein, 1992) and the relationship between power and blog use.

\section{Method}

This study used an online survey to explore the relationship between power and blog use among public relations practitioners. The questionnaire employed Porter and Sallot's (2005) power and Web use items. Blog credibility was measured through two questions previously used to assess media credibility (Kiousis, 2001; Johnson \& Kaye, 2004).

Participants were identified as being public relations practitioners through the Public Relations Society of America (PRSA) directory. From the directory, 1,125 individuals were randomly selected and then sent an e-mail to take the survey. Only 916 went to working e-mail addresses. Even though $37 \%$ of respondents aborted the survey before completing it, their responses were used in the analysis.

The invitation guaranteed respondents confidentiality and was sent in two waves a week apart in early 2006 . The overall response rate was $14 \%(N=132)$, with 87 practitioners responding in the first wave and 44 in the second. This response rate is similar to other Web surveys (Porter \& Whitcomb, 2003), those conducted on public relations practitioners (Porter \& Sallot, 2003, 2005), and online surveys of public relations students (Sha \& Toth, 2005).

\section{Results}

Consistent with national figures on blog use at the time, $9.8 \%$ of the respondents reported writing/maintaining blogs. Of those bloggers, $45.5 \%$ indicated that they discuss public relations on their blogs, $23.1 \%$ were blogging as a part of their job, and 76.9\% maintained personal blogs. Using a 5-point Likert scale ranging from never (1) to very frequently (5), half of the participants reported reading blogs written by others $(M=2.45$; S.D. $=1.08)$ and only about 1 in 10 indicated that they interacted by leaving comments on the blog $(M=1.52$, S.D. $=.86)$. In asking practitioners to predict the future use of blogs in the profession, practitioners disagreed with the statement that blogs were a passing $\operatorname{fad}(M=2.55 ;$ S.D. $=.78)$.

Indices were constructed from the Likert-type blog use items adapted from previous studies (Porter \& Sallot, 2005). Principal components factor analysis of the 16 items employed varimax rotation, producing three factors: routine information and research, interactive blog communication and issues identification.

H1. Practitioners who use blogs more frequently will perceive greater structural power within their organizations than practitioners who use blogs less frequently.

This hypothesis was not supported.

H2. Practitioners who use blogs more frequently will perceive greater expert power within their organizations than practitioners who use blogs less frequently.

An ANOVA of subjects' responses to the item "My informational use of blogs has empowered me as an expert in my organization" approached significant main effects for blog use for routine information and research factor $(F(1$, $117)=3.2, p<.078)$ and yielded significant main effects for blog use for issues identification factor $(F(1,117)=7.3$, $p<.01)$. There was no significant finding for the interactive blog communication factor.

H3. Practitioners who use blogs more frequently will perceive greater prestige power within their organizations than practitioners who use blogs less frequently.

This hypothesis was not supported.

H4. Owner-practitioners will use blogs more frequently than practitioners who are not owners.

A one-way ANOVA yielded significant main effects. Owner-practitioners used blogs more than non-owners for the interactive blog communication factor $(F(1,113)=8, p<.006)$ and for the issues identification $(F(1,112)=4.3$, $p<.05$ ) factor. 
RQ1 Will practitioners who write or maintain a blog have more power than those who do not blog?

A one-way analysis of variance found that practitioners who write or maintain a blog perceive that they have significantly more prestige power $(F(1,120)=23.4, p<.000)$ and expertise power $(F(1,119)=22.9, p<.000)$ than those practitioners who do not blog.

RQ2 How does PR practitioners' blog use relate to gender, age, professional tenure, race, education, and income?

A one-way analysis of variance found that practitioners who use blogs for routine information and research have been working in public relations significantly longer $(F(1,81)=3.8, p<.05)$. A one-way analysis of variance found that practitioners who use blogs for issues identification are significantly older $(F(1,77)=5.9, p<.018)$ and have been working significantly longer in public relations $(F(1,81)=9.1, p<.003)$. Males were marginally significantly more likely than females $(F(1,79)=3.2, p<.077)$ to use blogs for issues identification.

RQ3 Do practitioners of different affiliations (agency, corporate, not-for-profit, etc.) use blogs differently? A oneway ANOVA found that practitioners of different affiliations use blogs differently $(F(1,83)=2.452, p<.032)$ for routine information and research. Tukey follow-up procedures found that sole practitioners use blogs significantly more $(F(1,83)=2.5, p<.032)$ than practitioners of other affiliations.

RQ4 Do practitioners' levels of blog use affect amount of time they spend analyzing issues? A one-way analysis of variance found that practitioners who use blogs more for routine information and research believe that blogs help them sort through and analyze issues more quickly than practitioners who use blogs less for routine information $(F(1,112)=10.8, p<.001)$.

RQ5 Does practitioners' blog use for revenue generation relate to overall blog use? A one-way analysis of variance found that practitioners who use blogs more for issues identification believed that blogs generated additional revenue for their clients $(F(1,112)=5.9, p<.02)$.

RQ6 Is there a relationship between blog use and the credibility practitioners assign to blogs? Practitioners who were high users of blogs for routine information and research believe that blogs are more credible than practitioners who use blogs less for routine info at a marginally significant level $(F(1,111)=3.7, p<.06)$.

\section{Discussion}

Data here indicate that blogs are not being used as a standard public relations tool. Even so, it is clear that practitioners see the importance of blogs. This study notes those who use blogs are very different from those who do not, confirming other Internet use findings (Porter et al., 2001). Practitioners who blog feel they have more expertise and prestige power than those who do not blog. As such, this pilot study emphasizes the importance of examining the relationship between power and blog use. Those who write or maintain blogs were the only practitioners who saw increased prestige power for themselves as a result of their blog use.

The blog use factors here differed somewhat from similar, more general studies of pervasive technology among public relations practitioners (Porter \& Sallot, 2005). There appears to be a natural evolution of adoption for blog use in the reported factors. Practitioners begin using blogs routinely for informational purposes - seeking out alternative viewpoints, the latest news, and experimenting with blogs for research purposes. Then, use shifts to a more professional albeit passive - orientation. This issues identification factor allows practitioners to continue to use blogs for information but in a more strategic and professional manner. The final step in the evolution of blog use is to begin engaging in twoway communication. Here, users have already been indoctrinated into the quirky blog community, are aware of how their organization or client is being discussed in blogs, and are then ready to become an active part of the conversation as well by maintaining a blog or interacting on others'.

The findings here establish a clear link between blog use and power. Certainly merely using blogs will not provide a practitioner with power. Yet, it is evident that those with power continually drive themselves to not only stay current with trends in the industry, but they seek to lead the industry and establish protocols for using emerging tools that can be 
used to better target publics. Reading blogs provides a useful information tool for practitioners. However, practitioner bloggers believe that blogging provides a way for practitioners to truly establish themselves as prestigious experts in public relations. Future research should expand the initial work done in this pilot study, broaden the sample, and continue to explore the interesting relationship between power and blog use.

\section{Acknowledgements}

The authors would like to recognize Gennadi Gevorgan, Amanda M. Sapp, Amy Wilson, Aimee' Cardella, and Xiaowei Chen for their assistance with various parts of this project. A previous version of this paper was presented to the Public Relations Division at the annual conference of the National Communication Association in November 2006.

\section{References}

Anderson, R., \& Reagan, J. (1992). Practitioner roles and uses of new technologies. Journalism Quarterly, 69, 156-165.

Drezner, D. W., \& Farrell, H. (2004). The power and politics of blogs. Paper presented at the American Political Science Association annual meeting, Chicago.

Edelman \& Intelliseek (2005). Trust "MEedia": How real people are finally being heard, the 1.0 guide to the blogosphere for marketers and company stakeholders. Available at: http://www.edelman.com/image/insights/content/ISwp_TrustMEdia_FINAL.pdf.

Finkelstein, S. (1992). Power in top management teams. Dimensions, measurement, and validation. Academy of Management Journal, 35, 505-538.

Johnson, T. J., \& Kaye, B. K. (2004). Wag the blog: How reliance on traditional media and the Internet influence credibility perceptions of weblogs among blog users. Journalism \& Mass Communication Quarterly, 81, 622-642.

Kelleher, T., \& Miller, B. M. (2006). Organizational blogs and the human voice: Relational strategies and relational outcomes. Journal of ComputerMediated Communication, 11(2), article 1. http://jcmc.indiana.edu/vol11/issue2/kelleher.html.

Kiousis, K. (2001). Public trust or mistrust? Perceptions of media credibility in the information age. Mass Communication \& Society, 4, $381-403$.

Porter, L. V., \& Sallot, L. M. (2003). The Internet and public relations: Investigating practitioners' roles and World Wide Web use. Journalism \& Mass Communication Quarterly, 80, 603-622.

Porter, L. V., \& Sallot, L. M. (2005). Web power: A survey of practitioners' World Wide Web use and their perception of its effects on their decision-making power. Public Relations Review, 31, 111-119.

Porter, L. V., Sallot, L. M., Cameron, G. T., \& Shamp, S. (2001). New technologies and public relations: Exploring practitioners' use of online resources to earn a seat at the management table. Journalism \& Mass Communication Quarterly, 78, 172-190.

Porter, S. R., \& Whitcomb, M. E. (2003). The impact of contact type on Web survey response rates. Public Opinion Quarterly, 67, 579-588.

Sallot, L. M., Porter, L. V., \& Acosta-Alzuru, C. (2004). Practitioners' web use and perceptions of their own roles and power: A qualitative study. Public Relations Review, 30, 269-278.

Sha, B. L., \& Toth, L. E. (2005). Future professionals' perceptions of work, life, and gender issues in public relations. Journal of Public Relations Research, 31, 93-99.

Springston, J. K. (2001). Public relations and new media technology: The impact of the Internet. In Robert Heath (Ed.), Public relations handbook (pp. 603-614). Newbury Park, CA: Sage. 